\title{
EDUCAÇÃO AMBIENTAL: O BRINCAR COM A ENERGIA SOLAR EM ESCOLAS URBANAS DA AMAZÔNIA AMAPAENSE
}

\author{
Angela do Céu Ubaiara Brito ${ }^{1}$ \\ Alaan Ubaiara Brito ${ }^{2}$ \\ Raimunda kelly Silva Gomes ${ }^{3}$ \\ Reginaldo de Jesus Costa Farias ${ }^{4}$
}

\begin{abstract}
RESUMO
O trabalho discute conceitos de energia solar na percepção de crianças (7 a 10 anos), através de jogos, brinquedos e brincadeiras. Tem como objetivo entender o processo de sensibilização e mudança de hábitos e atitudes. A metodologia utilizada foi qualitativa de uso etnográfico educacional (DENZIN, 1989; ANDRÉ, 1978) que acompanhou as crianças das escolas públicas do Ensino Fundamental Anos iniciais. Os sujeitos da pesquisa foram 340 alunos e 10 professores. Os resultados mostram que a investigação possibilitou entender os jogos, brinquedos e brincadeiras que discutem a temática da energia solar no trabalho com a educação ambiental desenvolvido no âmbito de uma educação participativa. A educação ambiental possibilitou um pensar reflexivo das crianças por meio de jogos, brinquedos e brincadeiras.
\end{abstract}

Palavras- chave: Educação Ambiental. Energia solar. Brincar.

\section{ENVIRONMENTAL EDUCATION: PLAYING WITH SOLAR ENERGY IN URBAN SCHOOLS OF THE AMAPANEAN AMAZON}

\begin{abstract}
The work discusses concepts of solar energy in the perception of children (7 to 10 years), through games, toys and games. It aims to understand the process of awareness and change of habits and attitudes. The methodology used was qualitative of educational ethnographic use (DENZIN, 1989; ANDRE, 1978) that accompanied the children of public elementary schools. Early years. The subjects of the research were 340 students and 10 teachers. The results show that the research made it possible to understand the games, toys and games that discuss the theme of solar energy in the work with the environmental education developed in the scope of a participatory education. The environmental education made possible a reflexive thinking of the children through games, toys and games.
\end{abstract}

Keywords: Environmental education. Solar energy. Play

\footnotetext{
${ }^{1}$ Universidade do Estado do Amapá. E-mail: angela.brito@ueap.edu.br

${ }^{2}$ Universidade Federal do Amapá. E-mail: aubrito@unifap.br

${ }^{3}$ Universidade do Estado do Amapá. E-mail: rkellysgomes@yahoo.com.br

${ }^{4}$ Universidade do Estado do Amapá. E-mail: reginaldo.farias@ueap.edu.br
} 


\section{INTRODUÇÃO}

O presente artigo aborda a temática da Educação ambiental no que se refere a discussão sobre os conceitos de energia solar. Buscou-se compreender como as crianças de 7 a 10 anos entendem a energia solar por meio de jogos, brinquedos e brincadeiras.

As crianças compreendem os conceitos complexos quando tem 0 brincar como processo mediador. Investigar por meio de jogos, brinquedos e brincadeiras os conceitos de energia solar é possibilitar que a temática seja abordada de forma lúdica para os alunos. Fundamenta-se na literatura científica, nas obras de Piaget (1990), Vygotsky (1978) e Dewey (1940) que por meio do brincar as crianças conseguem aprender e compreender de forma lúdica conceitos mais complexos. A criança quando tem a possibilidade de brincar constrói conhecimentos e percorre o processo de ensino aprendizagem como ator de suas ações.

As pesquisas de Smith; Pellegrini e Goldsmiths (2008) concluem que as crianças investem entre $3 \%$ a $20 \%$ do seu tempo e de sua energia em brincadeiras. E após um período em que foram privados da oportunidade de brincar, o tempo destinado a essa atividade aumenta. A criança tem em sua natureza humana a necessidade de brincar e nesse processo vivencia o lúdico como parte de suas atividades cotidianas.

O brincar para as crianças, possibilita 0 desenvolvimento de competências e habilidades de aprendizagem que as preparam para as exigências da sociedade. Assim, o artigo discute como eixo fundamental a investigação de conceitos complexos que envolve a educação ambiental. E um dos conceitos que analisa nessa pesquisa é sobre as energias que vem do sol.

Desta forma investigou-se: Como as crianças aprendem por meio do brincar os conceitos das energias que são aproveitadas da energia solar? Tal investigação possibilitou entender como as crianças aprendem os conceitos complexos das energias direta e indireta do sol. Especificamente, identificou como os alunos entendem os diferentes tipos de energias renováveis que têm sua origem na luz do Sol (fotovoltaica, eólica, hidráulica, maremotriz, biomassa, 
etc.) e como a criança constrói o conceito de usar a energia com responsabilidade economizando para as gerações futuras.

A metodologia abordada foi qualitativa com uso do método etnográfico voltado para o lócus educacional que pesquisou cinco escolas da rede pública de Ensino Fundamental Anos iniciais e dez professores que trabalham com aulas que envolvem o brincar e a energia solar. As seções discutem a inserção dos Parâmetros Curriculares com temáticas ambientais nas aulas dos alunos, a educação ambiental (EA) e análise dos resultados. A pesquisa tem com contribuição a compreensão dos conceitos complexos para os alunos do Ensino Fundamental Anos iniciais referente ao estudo da energia solar que envolve a Educação Ambiental como norteador nas escolas.

\section{OS PARAMENTROS CURRICULARES NACIONAIS E A TEMÁTICA AMBIENTAL}

A inserção da EA, como processo pedagógico, ocorreu com a introdução da temática ambiental nos currículos escolares, oficialmente quando o MEC, lança em 1997 o documento intitulado PCNs (Parâmetros Curriculares Nacionais). Trata-se de um guia curricular organizado em disciplinas, tendo como principal finalidade "a contribuição para a formação de cidadãos conscientes, aptos para decidirem e atuarem na realidade socioambiental de um modo comprometido com a vida, com o bem estar de cada um e da sociedade, local e global" (BRASIL,1997 p. 25).

Os PCNs no ensino formal passaram a ser um desafio cotidiano para os (as) professores (as) e discentes, por ser compreendido como uma das principais reformas empreendidas pelo MEC, com a finalidade de modernizar as escolas no Brasil. Torales (2013) afirma que o próprio documento dos PCNs, que introduz oficialmente os temas transversais no sistema educativo, reconhece que a EA está longe de ser uma atividade tranquilamente aceita e desenvolvida, "porque ela implica mudanças profundas e nada inócuas" e o PRONEA propõe que o exercício da transversalidade precisa ser internalizado, por meio de espaços de interlocução bilateral e múltipla, por meio de diálogo interdisciplinar (BRASIL,1998 p.18).

Para Gallo (2001) nos PCNs, a interdisciplinaridade e a transversalidade são contidas como realidades próximas, porém distintas, pois enquanto a 
primeira diz respeito aos aspectos epistemológicos, a segunda refere-se aos aspectos pedagógicos, no entanto, ambas complementam-se, possibilitando uma nova dimensão social do processo educativo, que transcende o aprender pelo aprender.

Neste sentido, Macedo (1999) afirma que os PCNs pouco ajudaram no esclarecimento da diferença entre interdisciplinaridade, temas transversais e trabalho por projetos, não explicando como integrar os conteúdos com os temais transversais. Na realidade, não há mudanças na prática, em sala de aula, apenas adequações de planos e de programas curriculares aos conteúdos propostos nos PCNs. Neste contexto, percebemos que cabe a EA o desafio de garantir a formação cidadã no ensino formal e não formal.

Quanto as Diretrizes Curriculares Nacionais (DCN's), no 2 de 15 de junho de 2012, Loureiro e Viégas (2013, p.25) ressaltam que o caráter crítico, transformador e emancipatório da EA é colocado, como algo consensual, em todo o documento. No entanto, sabemos que esse consenso, principalmente no ambiente formal, está longe de se concretizar, pois a temática ambiental numa visão holística de educação, ainda é pouco difundida entre os (as) educadores (as).

Neste sentido, Cruz e Bigliardi (2012, p.10) ressaltam que as diretrizes deveriam considerar as necessidades planetárias, as discussões, os avanços históricos e experiências acumuladas, porque estes embasamentos fortaleceriam o reconhecimento do papel transformador e emancipatório da EA. Para tanto, seria necessário a revisão de conceitos de transversalidade e interdisciplinaridade contidos em sua normatização, que por sinal se encontra de forma reducionista e desarticulada. Para Loureiro e Viégas (2013:25) e Kaplan e Loureiro (2011:45) esses entendimentos nos levam a compreender porque não ocorrem mudanças na práxis do indivíduo socialmente e historicamente constituídos, levando os docentes a fragmentar a compreensão dos riscos socioambientais locais e globais evidenciadas na prática social.

Destaca-se que as legislações educacionais regulamentadoras (tais como decretos, resoluções e portarias) ainda não explicam como se dará, na prática, a abordagem desta temática nos estabelecimentos de ensino, e nem indicam os princípios para o seu trato transversal, nos níveis e modalidades da educação. Embora no capítulo III das DCN's, ocorra a proposição da 
organização curricular da EA, com destaque ao compromisso das instituições de ensino, que deve inserir a temática em seus projetos institucionais e pedagógicos desde a Educação Básica até a Superior, através de um currículo diversificado, considerando as diversidades sociais, éticas e culturais dos educandos, e incorporando valores de pertence, respeito e cooperação com o meio ambiente.

Portanto, não é demais enfatizar, embasado em Cavalcanti (2013); Loureiro (2015); Tozoni-Reis e Campos (2015, p.76), que é necessário uma práxis pedagógica desafiadora, numa nova organização de tempo-espaço na escola, assim como a adequação da matriz curricular, pois o atributo "ambiental" não deve ser usado para especificar um tipo de educação, mas como um elemento estruturante que demarca um campo político de valores e práticas político-pedagógica transformadora e emancipatórias.

Assim, a discussão da EA deve está presente nas séries inicias com eixo de mudança no cotidiano das crianças. É importante que as práticas sejam ação que envolva-as com atividade lúdicas voltadas para as questões ambientais, porém ressalta-se que se faz necessário a formação dos educadores para abordar a temática com jogos, brinquedos e brincadeiras.

No estado do Amapá as discussões acerca da EA ainda são preliminares, embora já tenha alguns resultados no Núcleo de Educação Ambiental, da Secretaria Estadual de Educação. Contudo, é necessário enfatizar a necessidade de inserir a EA efetivamente no currículo escolar de forma transversal, considerando a diversidade socioambiental ali existente. Neste sentido, Silva (2009) chama a atenção para a necessidade da educação considerar as peculiaridades naturais e sociais da Amazônia, que por sinal ainda aguarda por essa educação ambiental, que leve em consideração o modo de vida da população local, pois embora, se tenha tido experiências isoladas nas cidades, rios e florestas da região, é perceptível a urgência em refletir sobre o caráter da EA que tem sido efetivado na Amazônia brasileira, especificamente na região norte do Brasil.

Partindo desse pressuposto constata-se que a EA não tem sido efetivada no ambiente escolar como proposta pedagógica pautada nas concepções freirianas, o que segundo Damo et al. (2013) já era de se esperar, pois em uma sociedade fragmentada, constituída por elementos isolados, não 
se prestaria a resolução de problemas socioambientais concretos, nem ao incentivo de práticas benéficas ao meio ambiente, mas ao mero conservacionismo e a natureza na sua concepção ecológica, desconectada do meio ambiente humanizado. Embora a conscientização e o compromisso histórico com o meio ambiente impliquem na responsabilidade de fazermos e refazermos nossa história, como prática de liberdade e, consequentemente, de transformação social na formação política-cidadã dos indivíduos (FREIRE, 1980; 1999).

$\mathrm{Na}$ região norte enfrenta-se problemas ambientais como a falta de energia elétrica nas localidades ribeirinhas e um grande gasto de consumo na zona urbana, por parte da sociedade que discute pouco a questão da economia de energia, acredita-se que deve-se inclui nos currículos escolares possibilidades de ações que favoreçam a discussão sobre a EA na temática de energia solar.

\section{A EDUCAÇÃO AMBIENTAL NA EDUCAÇÃO DE CRIANÇAS}

A Educação ambiental é prevista na Lei 9597/99 que dispõe sobre a Política de Educação ambiental e um de seus objetivos é de incluir a discussão ambiental na educação de nossas crianças, pois entende-se que por meio da educação podemos de fato ter uma melhor qualidade de vida. O Art.1ํㅜ entende que educação ambiental é processo que está no eixo indivíduo e coletivo que possibilita a construção de valores sociais, conhecimentos, habilidades, atitudes e competências voltados para a conservação do meio ambiente, bem de uso comum do povo, essencial à sadia qualidade de vida e sua sustentabilidade (BRASIL,1999).

A escola é um espaço privilegiado de formação de nossas crianças e deve fazer uso da discussão ambiental não somente de forma teórica mais por meio de ações concretas que possibilite a vivência no cotidiano. A escola deve discutir o conhecimento e a percepção do ambiente que é necessário à condição de realização humana, "contudo no processo educativo isso se vincula a contextos específicos, a organizações sociais historicamente formadas" (MEC, 2007 p.70). Um dos eixos de discussão na educação das 
crianças é possibilitar a "consciência crítica do conjunto de relações que condicionam certas práticas culturais e, nesse movimento, superarmo-nos e às próprias condições inicialmente configuradas" (MEC, 2017 p.70).

Desta forma, a criança passa ser a um agente multiplicador da educação ambiental no ambiente que convive. A criança exerce ações que condizem com os princípios ambientais de preservação e sustentabilidade quando existe compreensão do conceito discutido.

Medina (2013) aborda em seu artigo "A formação dos professores em Educação Ambiental" experiências positivas nas quais as práticas realizadas com as crianças possibilitam que elas possam multiplicar o que aprendem em seu cotidiano, pois a ação realizada proporciona um pensar reflexivo. A criança a partir da vivencia se torna um sujeito ambiental consciente e sua ação é exemplo para os demais que convivem com ela. Porém, a autora levanta a situação de que isso é possível com a formação de professores que discute a temática ambiental como pedagogia interdisciplinar. Entende-se que a Educação Ambiental não está presente somente no dia árvore, da água ou do meio ambiente, mas faz parte do ambiente da escola como um todo.

Portanto, a Educação Ambiental para criança parte da experiência no cotidiano de interligar a teoria e a prática nas discussões com ações concretas para a vida, pois as crianças quando são incentivadas e compreendem o sentido da educação ambiental colocam em prática na percepção de que preservar é a melhor de forma de obter para as gerações futuras.

\section{A TEMÁtICA ENERGIA NA DISCUSSÃO DE JOGOS, BRINQUEDOS E BRINCADEIRAS}

A discussão da temática da energia discutida nos jogos, brinquedos e brincadeiras faz parte do projeto de extensão "Tenda educativa de jogos Brincar e aprender com a luz". Tal projeto nasceu da motivação do trabalho educativo com as crianças para que aprendam desde cedo que a Luz vem do Sol e é a principal fonte de energia do planeta. Também que o sol tem sua importância na produção de energia elétrica e como hoje se constitui um dos 
nossos bens ambientais mais preciosos e geradores de produção para qualidade de vida da humanidade.

Assim, o projeto percorre as escolas com a discussão da energia solar e tem a intenção de contribuir na educação da criança para o aprendizagem referente ao uso da energia e como economizá-la. Quando as crianças aprendem a importância do uso da energia têm a possibilidade de colocar em prática ações de preservação. As crianças transmitem conceitos e ações do uso responsável da energia para os seus familiares.

Ressalta-se que o trabalho por meio dos jogos, brinquedos e brincadeiras cria momentos de reflexão sobre 0 uso da energia, consequentemente cria, entre as crianças, uma rede de conscientização ambiental energética que é fundamental nas ações cotidianas hoje em dia.

O uso de jogos, brinquedos e brincadeiras para trabalhar com a educação de crianças na faixa etária de 4 a 10 anos fundamenta-se no sentido de que na literatura científica, Piaget (1990); Vygotsky (1978); Dewey (1940) identificam que, o brincar é o trabalho da infância e que por meio do brincar as crianças conseguem aprender e compreender de forma lúdica conceitos mais complexos. Segundo Vygotsky (1978) o brinquedo por si só é fonte de aprendizagem, serve como elemento mediador na educação das crianças a partir de 3 anos de idade. A mediação por meio do brincar é um elemento que permiti a criança refletir sobre o assunto em questão, uma vez que está envolvido na atividade (Brito:2015). Para Dewey (1976) o brincar é uma forma de experienciar e a criança aprender por meio da experiência.

A criança por meio de jogos, brinquedos e brincadeiras constrói conhecimentos e percorrem o processo de ensino aprendizagem como ator de suas ações (KISHIMOTO, 2007). O brincar para as crianças, oferece oportunidade para desenvolverem competências acadêmicas e sociais, preparando-as para as exigências da escola e do mundo externo. Destaca-se que por intermédio do brincar as crianças aprendem várias habilidades que contribuem para o processo de aprendizagem no mundo social e em suas vidas, tais como: colaboração (trabalho em equipe); conhecimento (matemática, ciência, linguagem, letramento, cultura, sociedade, história, geografia e outros); comunicação (oral e escrita); criatividade, e confiança. $O$ 
brincar confere às crianças habilidades fora da sala de aula, à medida que desenvolvem habilidades para a vida.

\section{PROCEDIMENTOS METODOLOGICOS}

A metodologia utilizada foi qualitativa que buscou investigar agrupamentos de crianças em relação aos conceitos de energia solar (DENZIN, 1989). Para as coletas de dados usou-se o método etnográfico educacional que observou as crianças das escolas públicas do Ensino Fundamental Anos iniciais. Os princípios etnográficos buscam a apropriação de significantes e significados próprios do grupo que está inserido. O método etnográfico de cunho educacional é um estudo voltado para questões voltadas ao ensino e aprendizagem que busca compreender como a criança constrói conceitos complexos, que no caso dessa pesquisa buscou investigar por meio do brincar conceitos de energia solar (ANDRÉ, 1978).

A área de estudo foram cinco (5) escolas da rede estadual de educação no município de Macapá, sendo que uma (1) da zona Norte, uma (1) escola no centro e três (3) na zona sul de Macapá. A investigação no lócus de cinco (5) escolas de ensino fundamental Anos iniciais da rede Estadual de ensino do Amapá selecionou crianças de 7 a 10 anos (sujeitos de pesquisa). Usou-se com instrumentos de pesquisa entrevistas abertas com 340 crianças, com a finalidade de compreender o conceito de energia solar e as demais energias que tem como fonte o sol. Também os alunos tiveram a oportunidade de brincar com jogos que discutem as temáticas sobre energia solar. Registrou-se a percepção do conceito de energia solar quando as crianças estavam do brincando com os jogos que discutem a temática. Os registros das atividades dos alunos foram realizados por meio do método etnográfico que possibilitou acompanhar os agrupamentos. Além disso, foi feita entrevista semiestruturada com dois professores de cada escola pesquisada, com um total de dez professores.

Os professores selecionados nas escolas campo de pesquisa foram os que trabalham com o brincar e a Educação Ambiental, especificamente, os que discutem o uso da energia com as crianças de forma interdisciplinar. A entrevista semiestruturada buscou compreender os conceitos de energia solar 
que são oportunizados nas atividades de brincar, no sentido de compreender como os professores discutem a temática. As entrevistas com os professores foram realizadas no local de trabalho.

Os dados foram tratados de forma qualitativa possibilitando a análise das respostas das crianças sobre o conceito de energia e o registro do brincar com os jogos e brincadeiras sobre a energia solar. Os dados tratados possibilitam as análises com base nos teóricos que discutem a aprendizagem por meio do jogo para compreender como as crianças internalizam o conceito por meio do brincar. Também se registrou as brincadeiras que foram analisadas com base nas observações e expressões das crianças.

Considerando os aspectos éticos da pesquisa as crianças e professores tiveram suas identidades preservadas ao longo da análise/apresentação dos resultados da pesquisa. As crianças foram identificadas como $\mathrm{C} 1, \mathrm{C} 2, \mathrm{C} 3$ e assim consecutivamente. Os professores foram identificados de P1, P2, P3, P4, P5, P6. As vozes dos sujeitos da pesquisa foram devidamente autorizadas pelos pais ou responsáveis.

\section{ENTENDENDO A EDUCAÇÃO AMBIENTAL NAS ESCOLAS LÓcUS DE PESQUISA}

Os dados analisados são referentes a pesquisa com cinco escolas públicas que receberam o projeto da Tenda Educativa de jogos: brincar e aprender com a luz, no período de fevereiro a dezembro de 2015. As escolas trabalharam com a Tenda Educativa de jogos com as crianças de 7 a 10 anos, que corresponde as turmas de $2^{\circ}$ a $5^{\circ}$ ano do $1^{\circ}$ ciclo do Ensino Fundamental. As escolas receberam a Tenda de jogos por uma semana e as demais atividades foram realizadas no laboratório de brincar que tem uma área de ciências com os jogos sobre a energia solar. A Tabela 1 mostra as escolas e 0 número de alunos que foram investigados.

Tabela 1 Escolas que fizeram parte da pesquisa

\begin{tabular}{l|l|l}
\hline Escolas & Número de alunos & Turmas \\
\hline Escola 1 & 60 & $2^{\circ}$ ano/3 ano \\
\hline Escola 2 & 80 & $4^{\circ}$ ano/4ํano \\
\hline Escola 3 & 60 & $3^{\circ}$ ano/5 ano \\
\hline
\end{tabular}




\begin{tabular}{l|l|l}
\hline Escola 4 & 60 & $4^{\circ}$ ano $/ 5^{\circ}$ ano \\
\hline Escola 5 & 80 & $2^{\circ}$ ano $/ 3^{\circ}$ ano \\
\hline Total & 340 & \\
\hline
\end{tabular}

Fonte: arquivo de pesquisa 2015.

As escolas trabalharam com as turmas de $2^{\circ}$ ao $5^{\circ}$ ano, em média com duas turmas do segmento, totalizando 340 alunos investigados na pesquisa. Os alunos selecionados para pesquisa possibilitaram a investigação pela etnografia educacional tem o sentido de vivenciar as ações, hábitos e atividades de um determinado grupo social educativo, que no caso dessa pesquisa foram 340 alunos que durante 10 meses nos possibilitaram essa vivencia (LÜDKE E ANDRÉ, 1986).

Os professores que fizeram parte da pesquisa obtêm as seguintes formação como mostra a Tabela 2.

Tabela 2- Professores que fizeram parte da pesquisa

\begin{tabular}{l|l|l}
\hline Escolas & Quantidade de professores & Formação \\
\hline Escola 1 & 2 & $\begin{array}{l}\text { Licenciatura em letras/licenciatura em } \\
\text { pedagogia }\end{array}$ \\
\hline Escola 2 & 2 & licenciatura em pedagogia \\
\hline Escola 3 & 2 & licenciatura em pedagogia \\
\hline Escola 4 & 2 & licenciatura em pedagogia \\
\hline Escola 5 & 2 & $\begin{array}{l}\text { Licenciatura em letras/licenciatura em } \\
\text { pedagogia }\end{array}$ \\
\hline Total & 10 & licenciatura em pedagogia \\
\hline
\end{tabular}

Fonte: arquivo de pesquisa 2015.

Foram 10 professores que se envolveram na pesquisa durante os meses de trabalhos com os jogos sobre a energia. Em entrevistas identificou-se que tem 2 professores que não possuem a formação de pedagógica para atuar no $1^{\circ}$ ciclo do ensino Fundamental. A Resolução CNE/CP no 1, de 15 de maio de 2006, que institui as Diretrizes Curriculares Nacionais para o Curso de Graduação em Pedagogia estabelece que o pedagogo deve atuar na docente do $1^{\circ}$ ciclo de fundamental, pois a formação é voltada para a compreensão dessa faixa etária, não admitindo a formação na demais áreas. No caso encontrado os professores licenciados em letras devem atuar no $2^{\circ}$ ciclo do ensino fundamental, com a disciplina especifica de Língua Portuguesa. Nas 
entrevistas podemos identificar a insegurança das professionais em atuar com as turmas usando a metodologia de jogos e brinquedos sobre a energia, uma vez que a formação que obtiveram na Universidade não possibilita a formação do $1^{\circ}$ ciclo do fundamental. A professora da Escola 1 cita o seguinte:

As crianças gostam de brincar e pedem todos os dias, mas entendo que devem ler mais e brincar menos, pois tem muito conteúdo para ser explorado (P1).

Entende-se que a falta de uma formação específica faz com que a professora tenha uma concepção de ensino conteudista na qual não consegue percebe as possibilidades de aprendizagem no jogos e brincadeiras que discute o tema da energia. Oliveira-Formosinho (2011) acredita que a metodologia baseada na transmissão com base nos conteúdos não possibilita a construção de aprendizado pela criança, apenas significa a reprodução das informações.

$\mathrm{Na}$ mesma escola a professora de formação em pedagogia contesta a concepção de que o conteúdo sistematizado é a base de tudo, pois acredita que:

As crianças aprendem muito quando estão mediados pelos jogos, brinquedos e brincadeiras. A aprendizagem que envolve o que eles mais gostam de fazer: o brincar, envolve as crianças de uma forma significativa. Eu percebo que quando exploro o conteúdo por meio do brincar as crianças se divertem, mas aprendem, como posso falar, existe aprendizagem de verdade (P2).

O fato da formação ter uma discussão voltada para os anos iniciais que envolve o lúdico como ferramenta pedagógica, a professora formada em pedagogia (P2) tem mais convicção de trabalhar com os jogos e brinquedos para a aprendizagem.

Kishimoto (1996) afirma que as escolas de Ensino Fundamental em sua maioria excluem o brincar de seu currículo, pois compreendem que as crianças têm o dever de estar em contato com conhecimento sistematizado apenas nos livros. Outro ponto a considerar é a falta de discussão sobre o meio ambiente, especificamente, sobre os recursos naturais relacionado as energias renováveis, nas quais são trabalhados em momentos específicos voltados para o meio ambiente e dia da árvore e água. A Tabela 3 mostra a percepção dos professores referente a discussão ambiental em suas escolas. 
Tabela 3 Percepção ambiental nas escolas

\begin{tabular}{l|l|l}
\hline Escolas & Professores & Percepção \\
\hline Escola 1 & P1 & $\begin{array}{l}\text { Na escola trabalhamos muito sobre a educação ambiental, } \\
\text { principalmente voltada para a questão do lixo, mas no dia 05 } \\
\text { de junho trabalhamos o meio ambiente e propomos ações. } \\
\text { Também fazemos o dia da água e é bem legal, realizamos o } \\
\text { banho de balde. }\end{array}$ \\
\hline Escola 2 & P2 & $\begin{array}{l}\text { Discutimos sempre quando o assunto nos permiti, quando } \\
\text { falamos dos animais, das plantas, rios e desmatamento, } \\
\text { mas no dia 05 de junho realizamos teatro e agora estávamos } \\
\text { discutindo a dengue. }\end{array}$ \\
\hline Escola 3 & P3 & $\begin{array}{l}\text { Posso dizer que a temática ambiental está sempre em } \\
\text { discussão, mas sinceramente é mais ações artificias, mas } \\
\text { acho que aqui falta prática. }\end{array}$ \\
\hline Escola 4 & P4 & $\begin{array}{l}\text { Educação ambiental está sempre presente com as crianças, } \\
\text { mas acho que ainda não entendemos direito como fazer na } \\
\text { prática, mas discutimos sim. }\end{array}$ \\
\hline Escola 5 & P5 & $\begin{array}{l}\text { Realizamos muitas atividades ambientais, eu gosto de } \\
\text { trabalhara a reciclagem e já fiz muito com os alunos. }\end{array}$ \\
\hline
\end{tabular}

Fonte: arquivo de pesquisa 2015.

Conforme descrito na Tabela 3, a educação ambiental existe como processo de discussão nas escolas, mas os relatos dos professores mostram que fazem parte de ações desconectadas de uma política ambiental para as crianças com um paradigma que esteja envolvido nos projetos das escolas. No relato de P4 deixa claro a falta de compreensão da prática ambiental como trabalho pedagógico com as crianças como espaço de formação. Já o relato de P1 confirma que as práticas são voltadas para os dias que a mídia seleciona para as campanhas nacionais sobre o meio ambiente.

Os relatos possibilitam analisar que tais professores discutiram pouco sobre a temática ambiental em sua formação, pois não conseguem sustentar uma prática pedagógica que envolva as crianças no cotidiano de forma interdisciplinar; a escola não fomenta uma discussão ambiental para a inclusão de uma política que possibilite a ação de forma sustentável nas formações com os professores e as crianças. Penteado (1994) discute que a prática ambiental 
vai fazer parte da ação metodológica se de fato os professores forem oportunizados por formações voltadas para o meio ambiente, caso contrário estaremos sujeitos a reprodução de práticas que comemoram dias voltados para o meio ambiente ou com práticas que percebem o ambiente como distante das crianças, na qual devem preservar uma floresta que não fazem parte.

Além disso, é perceptível nos relatos dos professores a dificuldade de expressar o que entendem por Educação Ambiental, focando em problemas ambientais, e alguns, de forma categórica, afirmam que Educação Ambiente se remete a coleta seletiva de resíduos sólidos. Porém, consideramos que os professores ainda não possuíam esclarecimentos suficientes sobre uma visão do que seria a Educação Ambiental holística e sua relação com os problemas ambientais existentes, o que percebemos refletido nas falas dos (as) professores (as), a permanente ocorrência das palavras "reciclar", "lixo", e "desmatamento", como foco do processo educativo de Educação Ambiental.

Guimarães e Cardoso (2014) afirmam que esta visão de EA acaba contribuindo para que esta seja vista como uma atividades pontual/esporádica, estanque, sem maiores reflexões com o todo, não abarcando a complexidade socioambiental da realidade, sendo que a EA holística é entendida na compreensão das contradições do sistema, que busca entender as múltiplas determinações políticas, econômicas, culturais do tempo histórico e a materialidade das relações do ser humano em sociedade com a natureza, e com outro ser humano.

Por outro lado, é perceptível a superficialidade, talvez, a perplexidade que expuseram ao serem questionados sobre EA, assunto ao mesmo tempo tão comentado e tão distante da realidade cotidiana, ao manifestar na expressão "não entendemos direito como fazer na prática". Logo, podemos evidenciar que apesar da EA na educação formal, ser compreendida como atividade integradora e transversal, os resultados deste estudo apontam para o fato de que, muitas vezes, a falta de acesso aos saberes em EA pelos (as) professores (as) tem dificultado sua efetivação no ambiente escolar. Resultados semelhantes foram encontrados por Tozoni-Reis et al. (2011a; 2013); Loureiro e Tozoni-Reis (2016), os quais alertam que a falta de acesso dos (as) professores (as) ao conjunto de saberes em EA necessários à sua 
prática educativa, para além do cotidiano da sala de aula, tem tornado difícil sua efetivação na sociedade atual.

Entende-se que a formação pedagógica é fundamental para fomentar a discussão de questões ambientais nas escolas, pois se os professores não proporcionarem a discussão em sala de aula, o trabalho da educação ambiental será realizado de forma artificial. Na etnografia educacional perguntamos a importância de trabalhar a temática da energia em sala. A Tabela 4 mostra o posicionamento de alguns professores sobre o tema.

Tabela 3 Posicionamento dos professores sobre o tema da energia

\begin{tabular}{l|l}
\hline Professores & Posicionamento \\
\hline P 1 & $\begin{array}{l}\text { É interessante trabalhar sobre a energia uma vez que percebemos aqui } \\
\text { na própria escola desperdício, saímos da sala e nem desligamos a luz. }\end{array}$ \\
\hline P 2 & $\begin{array}{l}\text { Vejo que as crianças somente podem preservar ou pensar na falta de } \\
\text { energia se forem provocadas a discussão. }\end{array}$ \\
\hline P 3 & $\begin{array}{l}\text { As discussão é pertinente e da forma que vem sendo proposta com as } \\
\text { cartilhas está bem lúdico e compreensivo. }\end{array}$ \\
\hline P 4 & $\begin{array}{l}\text { As crianças precisam pensar sobre a questão da energia e proporcionar } \\
\text { ações que provoquem a mudança. }\end{array}$ \\
\hline P 5 & $\begin{array}{l}\text { Eu acho que trabalhar com a educação ambiental precisamos: informar, } \\
\text { discutir e agir. Agir é a melhor metodologia com as crianças. }\end{array}$
\end{tabular}

Fonte: arquivo de pesquisa 2015.

Mesmo analisando que a prática ambiental nas escolas ainda é fragilizada e entendida por uma política de momento das datas comemorativas, existe uma certa preocupação entre os professores me discutir a questão ambiental e o tema da energia seria uma oportunidade de prática pedagógica diferenciadas.

Ressalta-se que antes de trabalhar com as crianças, o projeto ofereceu uma formação para os professores sobre temática de energia solar. A formação consistiu na parte técnica sobre o conceito de energia solar e na parte pedagógica sobre o trabalho com jogos, brinquedos e brincadeiras.

No entanto, Carvalho (2001) ressalta que colocar o (a) professor (a) diante de uma visão holística de EA, não significa necessariamente que este se veja enquanto "agente de mudança", pois a mudança implica no compartilhamento de experiências para a construção da identidade de um 
sujeito ecológico, tendo a EA, enquanto ação específica no fazer educativo no campo ambiental. Neste sentido, Loureiro (2012) declara que todos nós podemos mudar nosso comportamento por força de uma necessidade material ou por exigência do estado ou por imposição de alguém, sem que isso signifique que internalizou mudança de atitude. Concordamos com a afirmação de Loureiro (2012), embasado em Leff (2010), pois "para mudar é necessário querer mudar".

\section{BRINCANDO COM A ENERGIA SOLAR E COMPREENDENDO CONCEITOS}

As cinco escolas que receberam a Tenda de jogos proporcionaram as crianças vivencia de práticas ambientais por meio do brincar. Primeiramente as crianças entenderam por meio de uma cartilha educativa ( Figura 1) o conceito de energia solar. Com base na cartilha podemos entrevistar as crianças sobre o que compreenderam. Para a análise dos dados selecionamos 10 relatos das crianças nas escolas investigadas.

\footnotetext{
C1- A energia solar vem do sol, por meio do sol a energia passa para as placas e gera energia (Escola 1)

C2- O prof. Hélio explica que a energia solar é a que vem sol (Escola 1)

C3- A energia solar tem o sol para gerar nas placas (Escola 2)

C4- O sol gera a energia que não destrói os animais e as plantas (Escola 3)

C5. A energia que vem do sol pode ser a eólica que vem dos ventos por causa do sol.

C6- Tem energia do sol que se dá pela fotossíntese, a biomassa que vem das madeiras (Escola 3)

C7- A energia que tem aqui em Macapá em da hidrelétrica que também é do sol (Escola 4)

C8- A energia do sol não prejudica o meio ambiente (Escola 4).

C9- A energia que ainda não tinha visto era a energia maremotriz, ela também vem por meio do sol nas ondas (Escola 5)

C10- A energia solar é a melhor que tem, podia ser usada aqui que tanto sol (Escola 5).
}

Os relatos das crianças mostram que existe um entendimento sobre a energia solar, pois a cartilha explica por meio de exemplo os conceitos. Os estudiosos da infância (PINAZZA, 2012, BRITO; KISHIMOTO, 2015 E OLIVEIRA- FORMOSINHO et al, 2007) afirmam que os conceitos científicos são aprendidos pelas crianças quando elas podem discutir sobre eles. Brito e Kishimoto (2015, p. 18) corroboram afirmando que "as crianças, incialmente, 
criam hipóteses a partir de suas observações e constroem conceitos cotidianos". Assim, compreende-se que "não é possível a compreensão científica dos conceitos como algo generalizável na fase infantil, mas pode se ampliar conhecimentos para que mais tarde possam defini-los com mais clareza" (BRITO; KISHIMOTO, 2015, p.18). No entanto, o que mais interessou no estudo com os brinquedos solares foi a "investigação da criança no momento que se criam hábitos de refletir sobre a ação, pensar nas relações existentes e motivar a realização de atividades construídas de forma colaborativa" (BRITO; KISHIMOTO, 2015, p.18).

Entende-se que os conceitos sobre energia irão ficar mais claros para as crianças a partir do momento que realizarem atividades práticas e experienciar sobre a situação, no entanto percebe-se que o ponto inicial existe na compreensão de que o sol é o elemento que produz uma energia que não agride o meio ambiente.

As crianças foram proporcionadas ao brincar com a temática de energia. Um dos jogos que foi objeto de análise na etnografia em questão foi o jogo da memória. O jogo da memória sobre a energia solar contém 14 peças e a criança teria que memorizar a energia e seu elemento que a descreve. A crianças nas partidas não somente conseguiam memorizar as peças como atribuíam os conceitos, o relato de duas crianças mostra a aprendizagem em foco.

C76- essa energia é a biomassa que bem das madeiras, a sementinha fica na terra e vem o sol que ajuda a crescer e por meio da fotossíntese fica bem grande e depois a madeira é resíduo orgânico e pode gerar energia (Escola 5).

C89- A energia que vem do Sol pode ligara até um computador, mas primeiro passa pela placa fotovoltaica (Escola 4).

O relato nos remete a compreender que a partir dos jogos as crianças foram absorvendo os conceitos que pareciam abstratos descritos na cartilha. Autores como Oliveira-Formosinho (2007; 2011), Kishimoto (2009), Pinazza (2007) afirmam o brincar tem um valor para o desenvolvimento e aprendizagem da criança, bem como preconizam a atividade lúdica possibilita a reflexão das crianças. 
Mas a etnografia pode perceber que o professor que brincava com as crianças dialogava sobre os conceitos durante as partidas do jogo da memória. Essa observação etnográfica nos leva a analisar que os jogos foi o elemento mediador que conduziu outro elemento medidor na atividade, o professor como elo do processo de aprender. Compreende-se que a educação que se processa de forma lúdica e mediada não se organiza sem a interação entre as crianças, que nesse caso foi também com o professor que estava na brincadeira. A interação permeia a aprendizagem da criança, pois, é uma forma na qual partilham e aprendem informações na experiência de suas ações.

Dewey (1959b; 1959a) corrobora afirmando que a organização educacional não possibilita a interação da criança permiti a experiência de forma plena para a construção do conhecimento. Nesse caso, o jogo envolve as crianças em processo de interação que possibilita a aprendizagem.

A interação possibilita a criança a troca de experiências, a partilha de suas aprendizagens e, principalmente, a confrontar seus pontos de vistas e refletir internamente sobre eles permitindo o repensar e recriar do pensamento na ação reflexiva (DEWEY, 1959b).

Segundo Dewey (1929) é importante que o educador também mantenha um elo de interação com as crianças, pois, é responsável pelo ato educativo. A partir da interação é que possibilita as discussões dos temas de estudos entre as crianças na construção de uma educação que parte de um coletivo e não de um único indivíduo.

Os trabalhados pedagógicos de Dewey (1929) mostram que pela interação as crianças têm a possibilidade de discutir e analisar novas formas de conhecimento, pois, aguçam a curiosidade e encontram outras hipóteses tendo como consequência uma aprendizagem contínua. "O processo de educação é a ação recíproca na interação" em que se processam as relações sociais na vida em comunidade (DEWEY, 1964, p. 24).

Essa afirmação de Dewey foi observada nos jogos das crianças, como demostra o relato na partida do jogo da memória.

C54- lembra aí qual é mesmo a essa energia de onde vem? (Escola 1) C17- vou perguntar o professor se está certa essa carta? Esta sim. Energia solar e o sol (Escola 5). 
Os relatos demostram que a interação e o jogo que discute a energia fez com houvesse aprendizagem. Dewey (1934) entende que a brincadeira possibilita a interação entre as crianças como forma de aprendizagem. $O$ brincar é a expressão da atividade espontânea da criança e instrumento que favorece a educação e estabelece ligações entre as necessidades infantis e as exigências sociais. Segundo Dewey (1973, p. 103), o trabalho educativo e o brincar são definidos como ações que "não podem ser diferenciadas ou distinguidas um do outro pela presença ou pela ausência de interesse direto no que se está fazendo", pois, o brincar é um elo integrador e possibilita à criança fazer conexão entre suas experiências internas e externas.

Para a criança pequena, o brincar significa a ação de expressar, de realizar não somente seus desejos, mas de compreender as relações sociais no processo de interação. Dewey (1934, p. 109) define, na obra "Schools of tomorrow", que "brincando as crianças observam mais atentamente e deste modo fixam na memória e em hábitos muito mais do que eles simplesmente vivessem indiferentemente todo o colorido da vida ao redor".

Dewey (1960) atribuía um valor pedagógico ao ato de fazer, a experiência de fazer, pensar, organizar o brincar que leva ao interesse e ao esforço, ou seja, à aprendizagem. Nesse sentido, analisamos que o jogo da memória que possibilitou pensar sobre os conceitos de energia solar fez a diferença no processo porque tem como base a participação da criança nas construções de novas hipóteses e resoluções de problemas. A criança que vivencia contextos educacionais, em que existem a possibilidade da troca de experiências, a manipulação de objetos, a interação com os colegas mais avançados, a discussão dos problemas, as tentativas de experimentar e discutir o processo da experimentação e ainda divide suas dúvidas, anseios e perspectivas sobre o que vivencia no espaço educacional, tem uma gama de condições que estão, constantemente, no nível de aprendizagem. 


\section{CONSIDERAÇÕES FINAIS}

Os resultados desse estudo apontam que na prática funciona 0 isolamento dos professores (as), o que dificultava a compreensão da EA e sua interligação com os conteúdos curriculares e as questões socioambientais, econômicas e culturais existentes. Esta constatação não significa que os (as) professores (as) pesquisados não queriam vivenciar novas alternativas metodológicas interdisciplinares e transversais, muito pelo contrário, sentem sede de conhecimento e de formação didático pedagógica, que lhes possibilitassem a compreensão socioambiental da realidade local, e, principalmente, de alternativas metodológicas nas atividades pedagógicas curriculares nas escolas pesquisadas.

Os (as) professores (as) ressaltaram que é inevitável o medo da mudança e de implantação de projetos e de atividades que insiram a EA em suas práticas educativas- mostrando que é muito trabalhoso e requer tempo para a inserção nas atividades curriculares, explicando porque não foi possível inserir o tema ambiental no currículo escolar de forma inovadora e também potencializar o caráter crítico dos temas ambientais que emergem das contradições da sociedade.

Ressalta-se que a inserção da Educação Ambiental na infância é imprescindível, pois nessa fase a criança inicia sua formação sistematizada de aprendizagem. A EA deve assumir um caráter interdisciplinar usando a observação nas áreas abertas e verdes das escolas no sentido de estreitar a relação da criança com o ambiente que compõem seu espaço de aprendizagem, além de propor jogos, brinquedos e brincadeiras que envolva os elementos da natureza e temas específicos, como o caso da energia solar.

A investigação possibilitou entender os jogos, brinquedos e brincadeiras que discutem a temática da energia solar no trabalho com a educação ambiental desenvolvido no âmbito de uma educação participativa delinearam múltiplas aprendizagens para as crianças, as quais possibilitaram uma aprendizagem significativa na compreensão da energia solar e seu uso no cotidiano. 
Os jogos, brinquedos e brincadeiras foram instrumentos fundamentais para as crianças construírem conhecimento sobre os conceitos de energia solar. O brincar das crianças possibilitou troca de experiências para aprendizagem, pois as atividades lúdicas proporcionam aprendizagem com os conceitos de energia de uma forma diferenciada.

As crianças compreenderam os conceitos de energia solar e sua melhor utilização, pois as vozes das crianças mostram que no cotidiano houve mudança de atividade. As crianças se preocupavam com a energia da sala ligada quando saiam da sala.

Portanto, a EA tem sentido quando é vivenciada pelas crianças nas ações do cotidiano e as possibilidades de aprendizagem para sociedade com mais qualidade de vida está na formação das crianças como uma política ambiental.

\section{REFERÊNCIA}

ANDRÉ, M. D. A abordagem etnográfica na avaliação educacional. Rev. Tecnológica educacional, ano VII, n. ${ }^{\circ} 24$ set/out. pg. 9-12, 1978

BRASIL. Parâmetros Curriculares Nacionais (PCNs). Brasília: MEC/SEF, 1998

BRASIL. Parâmetros curriculares nacionais (MEC). Brasília: MEC/SEF, 1997

BRASIL. Estabelece as Diretrizes Curriculares Nacionais para a Educação Ambiental. DOU no 116, Seção 1, págs. 70-71, 2012.

BRASIL. Política Nacional de Educação Ambiental, Lei 9795. Diário Oficial da República Federativa do Brasil, Brasília, DF, 27 abr, 1999.

BRITO. A.C.U. 2015. Práticas de Mediação e o Brincar na Educação Infantil. São Paulo: Paco, 2015.

BRITO, A. C.U; KISHIMOTO, T.M. Por que as folhas e frutos caem? De onde vêm as borboletas? São Paulo: Pontão de Cultura/Ministério da Cultura/Polo Books, 2015.

CRUZ, R. G.; Bigliardi, R. V. Uma abordagem exploratória ao conteúdo epistemológico das diretrizes curriculares nacionais para educação ambiental. Revista Eletrônica do Mestrado em Educação Ambiental, 29: 15171256, 2012. 
CAVALCANTI, J. N. A. Educação ambiental: conceitos, legislação, decretos e resoluções pertinente e a formação continuada de professores em educação ambiental na Paraíba. Revista Eletrônica do Mestrado em Educação Ambiental, 1:30: 71-82, 2013.

DAMO, A.; Simões, C. S.; Moura, D. V.; Minasi, L. F.; Cruz, R. G. Paulo Freire, um educador ambiental: apontamentos críticos sobre a educação ambiental a partir do pensamento freireano. Revista desarrollo local sostenible, 5:13: 15-25, 2013.

DENZIN, N. K. The research act. Englewood Cliffs: N. J. Prentice Hall, 1989.

DEWEY, J. La escuela y la sociedad. Trad. de Domingos Barnes. Madrid: Francisco Beltrán, 1929.

DEWEY, J.1940. My pedagogic creed. In: Education today. New York: G. P. Putnam's Sons, 1940.

DEWEY, J. Schools of to-morrow. New York: E. P. Dutton, 1934.

DEWEY. J. Democracia e educación. In: escolar: mi credo pedagógico. Buenos Aires: Losada. 1959a.

DEWEY. J. Como pensamos: como relacionar o pensamento reflexivo com o processo educativo uma reexposição. 3. ed. São Paulo: Companhia Editora Nacional. 1959b.

DEWEY. J.Las escuelas de mañana. Buenos Aires: Losada. 1960

DEWEY. J. Dewey on education: selections. New York: Modern Library. 1964.

DEWEY. J. Vida e educação. São Paulo: Melhoramentos. 1973.

DEWEY. J. Experiência e educação. São Paulo: Companhia Editora Nacional. 1976

FREIRE, P. Conscientização: teoria e prática da liberdade: uma introdução ao pensamento de Paulo Freire. São Paulo: Cortez, 1980.

FREIRE, P. Educação como prática da liberdade. 23ํㅡㄹ ed. Rio de Janeiro: Paz e Terra. 1999.

GALLO, S.. Transversalidade e Meio Ambiente. Ciclo de Palestras sobre Meio Ambiente - Programa Conheça a Educação do CIBEC/INEP- MEC/SEF/COEA. 2001.

LUDKE M, ANDRÉ, M. Pesquisa em Educação: Abordagens Qualitativas. São Paulo, EPU. 1986.

KISHIMOTO, M. K.. Jogo, brinquedo, brincadeira e a educação. São Paulo: Cortez, 2009.

KISHIMOTO. T.M. Jogo, brinquedos e brincadeiras e Educação. São Paulo: Cortez. 1996. 
KAPLAN, L.; LOUREIRO, C. F. B. Análise crítica do discurso do Programa nacional de formação de educadores (as) ambientais -PROFEA: pela não desescolarização da educação ambiental. Educação em revista, 2:27: 177-196. 2011.

LOUREIRO, C. F. B.; VIÉGAS, A. Princípios normativos da educação ambiental no Brasil: abordando os conceitos de totalidade e de práxis. Pesquisa em educação ambiental, 1:8: 11-23. 2013.

LOUREIRO, C. F. B. Educação ambiental e educação para o desenvolvimento sustentável: polêmicas, aproximações e distanciamentos, In Educação ambiental no contexto escolar: um balanço crítico da década da educação para o desenvolvimento sustentável. Org. por Loureiro, C. F. B.; Lamosa, R. A. C. pp.58-67.Rio de janeiro: Quartet: CNPQ. 2015.

MEC. Vamos cuidar do Brasil: conceitos e práticas em educação ambiental na escola [Coordenação: Soraia Silva de Mello, Rachel Trajber]. - Brasília: Ministério da Educação, Coordenação Geral de Educação Ambiental: Ministério do Meio Ambiente, Departamento de Educação Ambiental: UNESCO. 2017.

MEDINA.N.M.. Panorama da educação ambiental no ensino fundamental Secretaria de Educação Fundamental - Brasília:MEC ; SEF. 2001

MACEDO, E. Parâmetros Curriculares Nacionais: A Falácia de Seus Temas Transversais, In Currículo: Políticas e Práticas. Org. por Moreira, A. F. B. pp. 43-58. Campinas: Papirus. 1999.

OLIVEIRA-FORMOSINHO, J.; FORMOSINHO, J.. PEDAGOGIA-EMPARTICIPAÇÃO: A perspectiva da associação criança. In: OLIVEIRAFORMOSINHO. J. (Org.). O espaço e o tempo na Pedagogia-emParticipação. Porto: Porto Editora. 2011.

PENTEADO, H. D. Metodologia do ensino de história e geografia. São Paulo: Cortez. 1994.

PINAZZA, M. A. John Dewey: inspirações para uma pedagogia da infância. In: Oliveira Formosinho, J.; Kishimoto, T. M.; Pinazza, M. A.(Orgs.). Pedagogia(s) da infância: Dialogando com o passado, construindo o futuro. Porto Alegre: Artmed. 2007.

PIAGET, J.A formação do símbolo na criança: imitação, jogo e sonho, imagem e representação. Rio de Janeiro: LTC. 1990.

SILVA, M. L. A educação ambiental e suas contribuições para a sustentabilidade da região amazônica: um estudo sobre as experiências desenvolvidas na floresta nacional do Tapajós. Revista interações, 11:122152. 2009.

SEGURA, D. S.B.. Educação Ambiental nas Escolas Públicas: da Curiosidade ingênua à consciência crítica. São Paulo: Annablume: Fapesp 2001 
SMITH, p. S; PELLEGRINI, A. P. GOLDSMITHS. Aprender por meio da brincadeira. University of London, Reino Unido, University of Minnesota, EUA. 2008.

TORALES, M. A. A inserção da educação ambiental no currículo escolar e o papel dos (as) professores (as): da ação escolar a ação educativa-comunitária como compromisso político ideológico. Revista Eletrônica do Mestrado em Educação Ambiental, v. esp: 1-15. 2013.

TOZONI-REIS, M. F. C.; Campos, L. M. L. A formação inicial de professores no fortalecimento da educação ambiental escolar: contribuições da pedagogia histórico-crítica, In Educação ambiental no contexto escolar: um balanço crítico da década da educação para o desenvolvimento sustentável. Org. por Loureiro, C. F. B.; Lamosa, R. A. C. pp. 105-120. Rio de janeiro: Quartet: CNPQ. 2015.

VYGOTSKY, L. S. Mind in society: the development of higher psychological processes. Cambridge, EUA: Harvard University Press. 1978. 